\section{reço de Transferência: Tratamento Contábil do Café da Manhã pela Hotelaria Paulistana}

\section{Gleice R. Guerra}

RESUMO: São Paulo é uma das cidades brasileiras que tem o parque hoteleiro mais desenvolvido, tanto em termos quantitativos como em tecnologias de gestão. Os estabelecimentos hoteleiros paulistanos, em sua maioria vendem o café da manhã incluído na diária. Para avaliar separadamente os resultados das áreas de Alimentos e Bebidas (A\&B) e de Hospedagem, é feito um repasse de receitas do Departamento de Hospedagem, que recebe 0 serviço do café da manhã, para o de $A \& B$, que fornece 0 serviço. Analisam-se os critérios utilizados pela hotelaria paulistana para estabelecer o preço de transferência, e em que medida o valor contábil de transferência auxilia a gestão a avaliar o desempenho dessas áreas.

PALAVRAS-CHAVE: hotelaria, alimentos e bebidas, operação hoteleira, transferência contábil, São Paulo.

ABSTRACT: São Paulo has the most developed hospitality industry in South America, both in terms of the number of rooms and in management techniques. As a marketing policy, the majority of hotels have included the cost of breakfast in the room rate. In order to best analyze the financial performances of the two departments, it is necessary to transfer the breakfast revenue from the Rooms to the Food and Beverage Division. The object of this paper is to analyze the criteria with which establish transfer values are established and to what extent that this accounting practice aids in the evaluation of the departmental performance.

KEYWORDS: transferprice, breakfast service, controller hospitality industry, São Paulo, Brazil.

1. Professora e coordenadora corporativa do Departamento Educacional de Hospedagem do Centro de Educação en Turismo e Hotelaria do SENAC-SP. Mestranda em Contabilidade e Controladoria pela Faculdade de Economia Administraça da Universidade de Sä Paullo.

Pel012-100 - Vila Marina - São Paulo - Brasil.

E-mail: gleice@sp.senac.br

\section{Introduçāo}

No Brasil, ao contrário do que ocorre nos Estados Unidos, é comum os hotéis incluírem no preço de venda das acomodações alguns serviços de alimentação, em geral motivados por questões mercadológicas. Quando isso ocorre, há a necessidade de atribuir a receita de alimentação ao departamento correspondente, a fim de que se possa avaliar separadamente o desempenho de cada um deles.

O objetivo deste trabalho é verificar e analisar os critérios que estão sendo utilizados pela hotelaria da cidade de São Paulo para transferir, especificamente, receita do serviço de café da manhã do Departamento de Hospedagem para o de Alimentos e Bebidas (A\&B). A análise do preço de transferência do café da manhã justifica-se pelo fato de este ser um serviço incluído na diária da maioria dos hotéis, e o procedimento contábil de transferência correspondente ser praticado por quase todos eles, estando inclusive previsto pelos principais softwares hoteleiros. Além disso, a transferência ocorre entre os dois maiores departamentos de operação hoteleira.

A pesquisa de campo foi realizada na cidade de São Paulo, cuja hotelaria é representativa. São Paulo possui não só um dos maiores parques hoteleiros nacionais, como também uma das maiores concentrações de hotéis de grande porte e de elevada categoria, em que grande parte desses hotéis são administrados por redes internacionais. Isso cquivale a dizer que esses hotéis têm controladoria de porte e qualificação suficientes para gerar informações gerenciais da melhor qualidade.

Este trabalho, em primeiro lugar, quantifica e qualifica a hotelaria da cidade de São Paulo e demonstra a importância das áreas de Hospedagem e de A\&B nos empreendimentos hoteleiros; apresenta, então, os estabelecimentos que incluem o café da manhã na diária, indicando a relevância de seu preço de transferência para análises gerenciais de desempenho. Posteriormente, realiza uma reflexão conceitual sobre preços de transferência, para depois apresentar a pesquisa realizada nos principais hotéis da cidade de São Paulo, por meio de entrevistas com a Controladoria retratando os critérios que vêm sendo adotados pela indústria hoteleira para o repasse $^{2}$ de café da manhã. Finalmente, apresenta algumas considerações que podem servir de indicação para as futuras pesquisas.

\section{Hotelaria Paulistana}

O Guia Quatro Rodas Brasil (2001) divide os meios de hospedagem da cidade de São Paulo em hotéis e flats. Os 96 estabelecimentos classificados como

2. Na hotelaria brasileira, o termo "repasse" é utilizado em substituição ao termo "transferência". 
TABELA 2 - TIPO DE ADMINISTRAÇÃO DOS HOTÉIS DA CIDADE DE SÃO PAULO

hotéis somam 12.854 unidades habitacionais; os 73 flats ${ }^{3}$ ofertam, para locação diária, 6.368 unidades habitacionais. Cabe ressaltar que esses números, aqui computamos os estabelecimentos existentes até setembro de 2000, não compõem a totalidade de meios de hospedagem da cidade ${ }^{4}$. Isso é relevante em uma cidade que veicula, a cada final de semana, duas ou três publicidades de lançamentos de distintos empreendimentos imobiliários com finalidade de exploração hoteleira.

O porte dos hotéis ${ }^{5}$ é definido em termos de número de unidades habitacionais (UH). Em relação ao porte, pode-se dizer que a cidade de São Paulo concentra estabelecimentos de tamanho médio e grande. Apenas 48 empreendimentos, $50 \%$ do total, são responsáveis por $76,3 \%$ da oferta de UH hoteleiras da cidade, como pode ser observado na tabela 1.

TABELA 1 - PORTE DOS HOTÉIS DA CIDADE DE SÃO PAULO

\begin{tabular}{ll|c|l|l}
\hline Porte & $\begin{array}{l}\text { Número } \\
\text { de Hotéis }\end{array}$ & $\begin{array}{l}\text { Total } \\
\text { de UH }\end{array}$ & $\%$ \\
\hline Grande & $\begin{array}{l}\text { + } 300 \mathrm{UH} \\
200 \text { a } 299 \mathrm{UH}\end{array}$ & 7 & 2,678 & \\
\hline Médio & 100 a $199 \mathrm{UH}$ & 29 & 2,882 & 43,3 \\
\hline \multirow{2}{*}{ Pequeno } & 50 a $99 \mathrm{UH}$ & 36 & 4,248 & 33,0 \\
\hline & $-50 \mathrm{UH}$ & 12 & 2,547 & \\
\hline TOTAL & 96 & 499 & 23,7 \\
\hline
\end{tabular}

Fonte: Guia Quatro Rodas Brasil (2001).

Para avaliar a hotelaria de São Paulo em termos qualitativos, também é interessante observar a quantidade de UH que são administradas por grandes redes hoteleiras, sejam nacionais sejam internacionais, conforme os dados apresentados na tabela 2.

3. Incluidos na classificaçāo apenas os condominios que oferecem mais de $50 \%$ de suas unidades labitacionais para hóspedes (Guia Quatro Rodas Brasil, 2001:9). O Guia Quatro Rodas explica também que "flat é aquele que, além de hóspedes diaristas, tem aptos [sic] com moradores, sejam proprietários ou inquilinos" (p. 9). Essa definiçāa não e amplamente aceita, uma vez que o mercado vem chamando de flat qualquer condominio que possua unidades habitacionais que constituam um poo/ hoteleiro, independentemente da proporção. Dessa forma, um condomínio cujo poo/ hoteleliro e formado por $100 \%$ das unidades habitacionais, portanto sem nenhuma unidade dedicada a resideencia de moradores ou inquilinos, ainda é, do ponto de vista juridico, um condominio com serviços hoteleiros, o que o enquadraria na categoria flat.

4. OGiuia esclarece, que "nāo publica todos os hotéis, pousadas e flats de uma cidade", mas "seleciona e classifica apena os que estejanı dentro dos critérios de avaliaçăo" (p. 8), que supostamente são critérios de qualidade de produto e de

5. A anălise de porte dos flats não é possivel de ser realizada, uma vez que as relações contratuais que regem o pool de e o que torna o porte da edificação variảvel mês a mês.

\begin{tabular}{l|c|l|c|c}
\hline Administração & $\begin{array}{l}\text { Número } \\
\text { de Hotéis }\end{array}$ & $\begin{array}{l}\text { Total } \\
\text { de UH }\end{array}$ & $\begin{array}{c}\text { Média } \\
\text { UH/hotel }\end{array}$ & $\%$ \\
\hline Rede Internacional & 24 & 5,150 & 215 & 40,1 \\
Rede Nacional & 20 & 3,033 & 152 & 23,6 \\
Independente & 52 & 4,671 & 90 & 36,3 \\
\hline TOTAL & 96 & 12,854 & & 100,0
\end{tabular}

Fonte: Guia Quatro Rodas Brasil (2001)

Esse critério também é relevante para os flats. Nesse caso, apenas duas redes hoteleiras administram $45 \%$ dos empreendimentos classificados pelo Guia Quatro Rodas (2001), conforme pode ser observado na tabela 3.

\section{TABELA 3 - TIPO DE ADMINISTRAÇÃO DOS FLATS DA CIDADE DE SÃO} PAULO

\begin{tabular}{l|c|c|l|l}
\hline Administraçăo & $\begin{array}{c}\text { Número } \\
\text { de Flats }\end{array}$ & $\begin{array}{c}\text { Total } \\
\text { UH }\end{array}$ & $\begin{array}{l}\text { Média } \\
\text { UH/flat }\end{array}$ & $\%$ \\
\hline Transamérica - Rede Nacional & 10 & 1,050 & 105 & 13,5 \\
Parthenon/Accor - Rede Internacional & 23 & 2,064 & 90 & 26,5 \\
Outras redes e flats independentes & 40 & 4,671 & 117 & 60,0 \\
\hline TOTAL & 73 & 7,785 & 107 & 100,0 \\
\hline
\end{tabular}

Fonte: Guia Quatro Rodas Brasil (2001)

Os flats, entretanto, possuem em geral uma estrutura administrativa pequena. Dados da Horwath Consulting \& Soteconti Auditores Independentes (1999) mostram que os flats da cidade de São Paulopossuíam em média apenas 0,04 funcionário na área administrativa por UH, contra 0,08 nos hotéis da região sul e sudeste. Ao considerar, ainda, que o número médio de apartamentos integrantes do pool hoteleiro era de 67 em 1998, observa-se a existência média de 2,7 funcionários por empreendimento, para realizar todas as funções financeiras, contábeis, de recursos humanos e de suprimentos (compras e almoxarifado). De fato, nota-se no mercado que a maioria das funções administrativas nos flats são terceirizadas, e que são raros os empreendimentos que podem, em função de sua estrutura organizacional, dedicar tempo para análises de desempenho com alguma profundidade. Além disso, muitos flats contam com o próprio restaurante terceirizado, quando então inexiste o repasse da receita do café da manhã, sendo pago o preço de venda da empresa arrendatária. Sendo assim, optou-se por não pesquisar o preço de transferência do café da manhã 
nos flats, por julgar que os hotéis possuem melhores condições de manter sua contabilidade gerencial de forma mais criteriosa.

Dessa forma, e em função do objetivo deste trabalho ser a realização de um estudo exploratório qualitativo, decidiu-se por selecionar os hotéis da cidade de São Paulo que seriam pesquisados a partir dos seguintes critérios:

- os 30 hotéis mais qualificados conforme classificados pelo Guia Quatro Rodas Brasil (2001): os hotéis com mais qualidade de prestação de serviços são os que, em geral, cobramuma diária maisalta, portanto têm mais condições de manter um quadro de funcionários adequado para dedicar-se à controladoria. Além disso, são os hotéis que realizaram maiores investimentos por $\mathrm{UH}$, o que implica, na maioria das vezes, maiores cuidados com o controle de desempenho;

- os hotéis de médio e grande porte não contemplados pelo critério acima, ou seja, os que possuem mais de $100 \mathrm{UH}$. O alto investimento total, nesse caso, foi o fator relevante para sua inclusão, bem como a tendência de existir uma controladoria melhor estruturada;

- desconsiderar os flats de qualquer porte ou categoria, pelos fatores já apresentados.

A seguir serão expostos os motivos pelos quais é relevante o estabelecimento de um preço de transferência de café da manhã adequado aos propósitos de gestão, a partir da constatação da importância das áreas de Hospedagem e de A\&B na hotelaria.

\section{Hospedagem e Alimentos e Bebidas}

Na década de 1920, um grupo de contadores, a pedido da Associação de Hotéis de Nova York, desenvolveu o Sistema Uniforme de Contabilidade para Hotéis (SUCH) - Uniform System of Accounts for Hotels. O SUCH foi adotado formalmente em março de 1926, e desde então vem sendo revisado e atualizado. O SUCH não é apenas um sistema de contas recomendado, como também formaliza toda a estrutura e departamentalização que hoje é utilizada correntemente pela indústria hoteleira.

A ampla utilização do SUCH garante a uniformidade de linguagem e classificação de ativos, passivos, receitas e despesas, que permitem comparar e analisar, com alguma segurança, os resultados de operações distintas.

Conforme o SUCH, a indústria hoteleira fornece serviços e produtos de hospedagem, alimentos e bebidas (A\&B), eventos, telefonia e lavanderia ${ }^{6}$. Os resultados proporcionados pela oferta de Hospedagem e A\&B são os mais significativos para a hotelaria média nacional, conforme pode ser observado na tabela 4 .
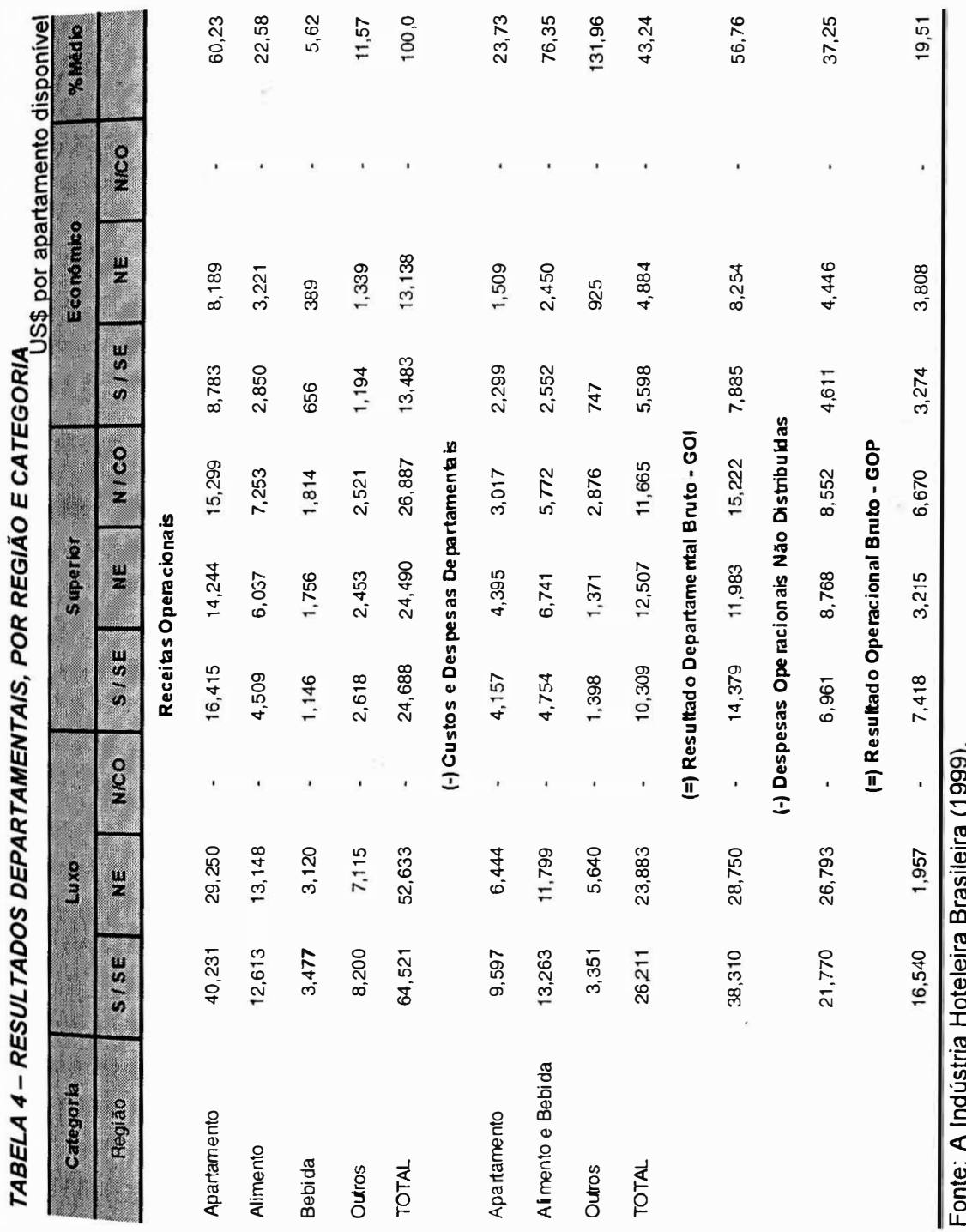

6. Algumas variações podem ser encontradas entre os hotéis, mas esses são os serviços mais comuns. 
Em 1998, a receita de Hospedagem (diárias de apartamentos deduzidos impostos, taxas de serviço, café da manhã e descontos) chegou a representar $66,5 \%$ das receitas dos hotéis superiores do sul/sudeste. O grupo de hotéis em que a receita de diárias teve menor significado foi o de categoria superior do norte/centro-oeste, mas, mesmo assim, ainda representou $56,9 \%$ das receitas operacionais dos hotéis

Os custos e despesas do departamento de Hospedagem ${ }^{7}$ representaram de $20 \%$ a $30 \%$ da receita departamental. O SUCH classifica a depreciação como despesa não operacional ${ }^{8} \mathrm{e}$, em última análise, a receita de Hospedagem é essencialmente uma remuneração do investimento. Essa remuneração, portanto, não está classificada dentre os custos e despesas departamentais. O resultado de Hospedagem, em média entre $70 \%$ e $80 \%$ da receita departamental, é o que possibilita aos hotéis arcar com as despesas operacionais não distribuídas (não rateadas) de administração, marketing, energia e manutenção.

A receita de Alimentos é proveniente da venda de produtos e serviços de restaurante, room service, banquetes e serviços similares, além do café da manhã. $\mathrm{O}$ café da manhã, portanto, é classificado como alimento.

A receita de café da manhã pode corresponder ao café de passantes ou de hóspedes, incluso ou não na diária, servido no restaurante ou no apartamento. Algumas vezes, ainda, o café está incluso na diária somente quando servido no restaurante, e é cobrado como extra quando solicitado ao room service. Nesse caso, a receita é atribuída ao departamento de $\mathrm{A} \& \mathrm{~B}$ em duplicidade

A receita de Bebidas é a proveniente das vendas de bebidas. As receitas de $\mathrm{A} \& \mathrm{~B}$, somadas, variam conforme a categoria e a localização dos hotéis entre $22,9 \%$ (superior, sul/sudeste) e 33,7\% (superior, norte/centro-oeste) das receitas operacionais totais. Os custos e despesas ${ }^{9}$ do departamento situaram-se, em média, entre 60,8\% (superior, norte/centro-oeste) e 78,7\% (superior, nordeste) das receitas do departamento. A Pannell Kerr Forster, uma empresa de auditoria internacional especializada na indústria da hospitalidade, encontrou resultados parecidos em sua pesquisa: média de 76,7\% para os estabelecimentos norte-americanos (Apud Schmidgall, 1990: 88).

O resultado de A\&B chegou a US $\$ 4.469,00$ por apartamento disponível, em média, nos hotéis de luxo da região nordeste em 1998. Os hotéis econômicos, onde pouco ou nenhum serviço de A\&B é oferecido, tiveram também resultados expressivos: US\$ 53,00 por apartamento disponível no sul e sudeste, alcançando US\$1.160,00 no nordeste.

Entretanto, sempre que o hotel inclui o café da manhã na diária cobrada, seu repasse está refletido nos resultados de $\mathrm{A} \& \mathrm{~B}$, através de um preço de transferência.

7. Incluem salários e encargos de recepção, govemanç̧a, reservas e portaria. Outras despesas incluem material de Jimpeza, lavanderia, enxoval, amentires, uniformes, despesas coml reservas, comissão aos agentes de viagens, etc 8. Essa classificcą̧ão seria discutivel. Entretanto, não faz parte do escopo deste traballto entrar nesse mérito.

9. Incluem os custos diretos de alimentos e bebidas, os salarios e encargos da cozinha, restaurantes, bares, room servic
A transferência é feita da receita de Hospedagem para Alimentos e Bebidas, e os critérios para sua definição são arbitrados pela gestão. O preço de transferência é definido de forma unitária, e o valor total a ser transferido é o resultado do número de pessoas hospedadas (quer tenham tomado o café da manhã quer não) em determinado período multiplicado pelo preço de transferência definido. Por exemplo, um hotel com $100 \mathrm{UH}$, que obteve uma taxa de ocupação de $65 \%$ durante o ano, com uma média de 2,5 hóspedes por UH, vendeu 23.725 diárias para 59.312 hóspedes. Se o preço de transferência do café é de US\$3,00, isso resulta em uma receita de A\&B da ordem de US\$180 mil, ou US\$1.800 por apartamento disponível.

A inclusão do café da manhã na diária cobrada é muito comum no Brasil, ao contrário do que ocorre nos Estados Unidos. O Guia Quatro Rodas Brasil (2001) listava 96 hotéis em funcionamento na cidade de São Paulo, além de 73 "flats". Dentre os 169 estabelecimentos de hospedagem, apenas 12 hotéis, todos de alto padrão ${ }^{10}$, são citados pelo Guia como empreendimentos que não oferecem o café da manhã incluído na tarifa de hospedagem, conforme os dados da tabela 5.

\section{TABELA 5 - ESTABELECIMENTOS HOTELEIROS DE SÃO PAULO COM CAFÉ DA MANHÃ NÃO INCLUÍDO}

\begin{tabular}{l|c}
\hline \multicolumn{1}{c|}{ Hotel } & Classificação \\
\hline Renaissance & $1^{\circ}$ \\
Gran Meliá São Paulo & $2^{\circ}$ \\
Maksoud Plaza & $3^{\circ}$ \\
Sofitel São Paulo & $4^{\circ}$ \\
L'Hotel & $5^{\circ}$ \\
Inter-Continental São Paulo & $6^{\circ}$ \\
Caesar Park & $7^{\circ}$ \\
Sheraton Mofarrej & $8^{\circ}$ \\
Grand Hotel Mercure & $10^{\circ}$ \\
São Paulo Hilton & $13^{\circ}$ \\
Crowne Plaza & $14^{\circ}$ \\
Novotel São Paulo Center Norte & $16^{\circ}$ \\
\hline
\end{tabular}

Fonte: Guia Quatro Rodas Brasil (2001).

Sabe-se que o enfoque dessa publicação privilegia atender ao turista particular que não viaja em grupos, e que freqüentemente não utiliza qualquer tipo de

10. Novamente, questões mercadológicas explicam a não inclusão do café da manhã na tarifa praticada por esses estabelecimentos: os hotéis de alto padrão têm alto porcentual de hóspedes estrangeiros, dentre os quais os norte- 
intermediário para sua reserva. Assim mesmo, constataram-se alguns hotéis citados na tabela 5 que comercializam o café da manhã incluído na diária da hospedagem de grupos ou na venda de pacotes.

\section{Preço de Transferência}

O conceito de valorização monetária de uma transferência interna de produtos ou serviços, através de um preço, está relacionado com a descentralização das empresas, e com o estabelecimento de centros de responsabilidade" para cada gestor de uma subunidade de uma organização. O que justifica a utilização de um preço de transferência cobrado entre subunidades de uma mesma empresa é a necessidade de avaliar, individualmente, o desempenho de atividades interdependentes. O preço de transferência é, portanto,

um mecanismo capaz de normalizar a intermediaçāo das relações [entre subunidades], de forma que as avaliações de desempenhos e de resultados sejam o mais justas e corretas possivel (Pereira e Oliveira, 1999: 418).

Preço de transferência pode, portanto, ser definido como o

preço que uma subunidade (setor, departamento, divisão, etc.) cobra por um produto ou serviçofornecido a outra subunidade da mesma organizaçāo (Horngren, Foster e Datar, 1997, p. 708)

Entretanto, a avaliação individual de subunidades deve ter em vista privilegiar o resultado global da organização. Mauro (1991:93) procura, através do estudo de preços de transferência,

desenvolver parâmetros para aferição dos niveis de eficácia das operações da organização do ponto de vista de suas partes, tornando possivel uma avaliação precisa da qualidade do trabalho $[\ldots]$ de seus gestores. 11. Sobre centros de responsabilidade (responsibility accounting) ver, por exemplo, Pereira (1999) e Moncarz e
Portocarrero (1986)
Nesse sentido,

o conceito de preço de transferência deve incorporar características que estimulem os gestores a buscarem, de forma lúcida e objetiva, o sucesso da empresa como um todo por meio de sua atuação numa área em particular (Pereira e Oliveira, 1999:418).

Existem três modelos gerais para definição do preço de transferência: custos, mercado e negociação entre os gestores, conforme demonstrado na tabela 6 . Há ainda a proposta de utilização do conceito econômico de custo de oportunidade (Mauro, 1991; Pereira e Oliveira, 1999), também demonstrada na tabela.

O modelo baseado em custos pode ter por referência o custo total realizado, ouseja, a somatória dos custos variáveis com os fixos; o custo variável, seja realizado seja padrão; o custo marginal, entendido como o custo para disponibilizar uma unidade adicional do produto ou serviço, dado determinado volume de produção; ou ainda um desses tipos de custos mencionados acrescido de uma margem. Outras variações podem ser encontradas, como custo pleno orçado, custo de fabricação (absorção) ou combinações dos tipos mencionados.

O modelo baseado em preços de mercado determina o preço de transferência através do preço de venda do produto ou serviço que é transferido, utilizando como base o preço médio praticado pelo mercado. Uma variante é excluir do preço de mercado as despesas que a organização não incorre ao transacionar o produto ou serviço internamente (por exemplo, despesas de frete e embalagem), ajustando-o.

Pereira e Oliveira (1999), Mauro (1991) e Horngren, Foster e Datar (1997) não citam a possibilidade de adotar o preço praticado como parâmetro para o preço de transferência, muito provavelmente por considerarem que o produto ou serviço transferido é um produto intermediário, não um produto final. Ou, ainda, por não preverem a venda de produtose/ou serviços que nunca encontrarão correspondentes exatos no mercado.

No caso do café da manhã hoteleiro, o serviço pode ser oferecido pelo departamento de Hospedagem, incluído na diária, ou pelo departamento de A\&B como um serviço extra, quer para passantes, quer para hóspedes, que, por qualquer motivo, não o tenham incluso ${ }^{12}$. Portanto, existe sempre um preço de venda praticado pelodepartamento de A\&B para clientes em geral, e existe a possibilidade de A\&B tratar Hospedagem como um cliente qualquer, oferecendo-lhe o café pelo preço praticado.

12. Mesmo os estabelecimentos que não possuem um restaurante aberto ao público e vendem todas as diárias com o café
da manhã incluido prevêem unm preço para café extra, no minimo para os casos de early check in: situação em que da manhã incluido prevêem um preço para café extra, no minimo para os casos de early check in: situaçāo em que e tem incluido apenas o café da manhā do dia posterior, mas toma o café também no dia da chegada ao hotel. 


\section{TABELA 6 - MODELOS DE PREÇO DE TRANSFERENCIA}

\begin{tabular}{|c|c|c|c|c|}
\hline Base & Tipo & $\begin{array}{l}\text { Metodologia para } \\
\text { determinar Preço de } \\
\text { Transioróncia }\end{array}$ & Pontos Fortes & Pontos Fracos \\
\hline \multirow[t]{5}{*}{ Custos } & $\begin{array}{l}\text { Custo total } \\
\text { realizado (full } \\
\text { cost) }\end{array}$ & $\begin{array}{l}\text { custos fixos + variáveis } \\
\text { dividido pelo volume de } \\
\text { produçăo de determinado } \\
\text { periodo (custeio por } \\
\text { absorçāa) }\end{array}$ & & $\begin{array}{l}\text { permite repassar eficiên- } \\
\text { ciaśineficiências;distorç̧ōes } \\
\text { causadas pelo rateio de } \\
\text { custos fixos; não permite } \\
\text { identificar resultado gerado } \\
\text { nas atividades }\end{array}$ \\
\hline & $\begin{array}{l}\text { Custo } \\
\text { variaivel } \\
\text { realizado }\end{array}$ & $\begin{array}{l}\text { custos variàveis incorridos } \\
\text { (custeio variável) }\end{array}$ & $\begin{array}{l}\text { custos fixos não } \\
\text { são transferidos }\end{array}$ & $\begin{array}{l}\text { permite repassar eficiências } \\
\text { lineficiências; não permite } \\
\text { identificar resultado gerado } \\
\text { nas atividades }\end{array}$ \\
\hline & $\begin{array}{l}\text { Custo } \\
\text { variàuel } \\
\text { padrăo }\end{array}$ & $\begin{array}{l}\text { custo cientificamente } \\
\text { predeterminado e que } \\
\text { deveria ter ocorrido }\end{array}$ & $\begin{array}{l}\text { custos fixos não } \\
\text { são transferidos: } \\
\text { pode impedir } \\
\text { transferência de } \\
\text { neficiência }\end{array}$ & $\begin{array}{l}\text { não permite identificar } \\
\text { resultado gerado nas } \\
\text { atividades }\end{array}$ \\
\hline & $\begin{array}{l}\text { Custo } \\
\text { marginal }\end{array}$ & $\begin{array}{l}\text { base em volume, custo e } \\
\text { preço que otimizam lucro }\end{array}$ & & $\begin{array}{l}\text { desprezadas condiçōes } \\
\text { relevantes de mercado; pode } \\
\text { causar mesmas distorçôes do } \\
\text { full cost }\end{array}$ \\
\hline & $\begin{array}{l}\text { Custo mais } \\
\text { margem }\end{array}$ & $\begin{array}{l}\text { custo-base (total realizado, } \\
\text { variävel realizado, marginal } \\
\text { ou padrão) mais mark up }\end{array}$ & & $\begin{array}{l}\text { induz a resultados ilusórios; } \\
\text { incorpora, além das defíci- } \\
\text { êcias do conceito de custo } \\
\text { utilizado a distorção causada } \\
\text { pela arbitragem da margem }\end{array}$ \\
\hline \multirow[t]{2}{*}{ Mercado } & $\begin{array}{l}\text { Preços } \\
\text { correntes de } \\
\text { mercado }\end{array}$ & $\begin{array}{l}\text { preço de mercado, que } \\
\text { pode ser médio }\end{array}$ & $\begin{array}{l}\text { custos não } \\
\text { influenciam determi- } \\
\text { naçąo do preço }\end{array}$ & $\begin{array}{l}\text { incorpora elementos que a } \\
\text { empresa não incorre }\end{array}$ \\
\hline & $\begin{array}{l}\text { Preço de } \\
\text { mercado } \\
\text { ajustado }\end{array}$ & $\begin{array}{l}\text { preço de mercado ajustado } \\
\text { pela exclusão de eventos } \\
\text { que não ocorrem em } \\
\text { transaçōes internas }\end{array}$ & $\begin{array}{l}\text { preço não } \\
\text { incorpora } \\
\text { elementos nảo } \\
\text { incorridos }\end{array}$ & $\begin{array}{l}\text { incorpora distorçōes } \\
\text { causadas por variaveis de } \\
\text { difficil estimativa }\end{array}$ \\
\hline Negociação & $\begin{array}{l}\text { Negociação } \\
\text { entre } \\
\text { gestores }\end{array}$ & $\begin{array}{l}\text { negociaçáo entre gestores, } \\
\text { seja ou náo a partir de } \\
\text { parâmetros de referência }\end{array}$ & & $\begin{array}{l}\text { valor influenciado pela } \\
\text { habilidade de negociaçáo e } \\
\text { "poder pollitico" dos gestores }\end{array}$ \\
\hline Econômica & $\begin{array}{l}\text { Custo de } \\
\text { oportunidade }\end{array}$ & $\begin{array}{l}\text { área expedidora: benefício } \\
\text { gerado pela melhor } \\
\text { alternativa preterida em } \\
\text { função da transferência; } \\
\text { àrea receptora: menor } \\
\text { preço de mercado }\end{array}$ & $\begin{array}{l}\text { custos fixos não } \\
\text { são transferidos; } \\
\text { impede transferên- } \\
\text { cia de Ineficiência; } \\
\text { custos não influen- } \\
\text { ciam determinaçăo } \\
\text { do preço }\end{array}$ & $\begin{array}{l}\text { possibilidade de } \\
\text { estabelecimento de preço } \\
\text { duplo }\end{array}$ \\
\hline
\end{tabular}

Fonte: adaptado de Pereira e Oliveira (1999)
Por mais que a composição do café da manhã de dois estabelecimentos seja exatamente a mesma (em termos de alimentos oferecidos), variações no nível de prestação de serviços ou, ainda, tão sutis e intangíveis como na localização e na ambientação do serviço, tornam um café da manhã incomparável a outro. O preço praticado é, nesse caso, a única referência daquele "mercado", correspondendo ao preço médio ofertado. Horngren, Foster e Datar( 1997:642) explicam, nesse sentido, que a utilização do preço de mercado só "conduz a decisões ótimas quando são satisfeitas três condições", dentre elas: "(1) o mercado intermediário [ser] perfeitamente competitivo" e "(2) [ser] mínima a interdependência entre as subunidades", o que não ocorre no caso do café da manhã hoteleiro.

A adoção do método de negociação entre os departamentos normalmente envolve ter custos ou mercado como pontos de partida, e muitas vezes ocorre em situações em que os responsáveis por cada departamento podem optar por vender ou comprar interna ou externamente.

Pereira e Oliveira (1999:418-9) ensinam que o preço de transferência deve auxiliar a gestão a:

- permitir uma constante avaliação dos niveis de eficiência e eficácia da empresa, a partir das relaçōes econōmicas entre suas atividades;

- permitir avaliaçōes de desempenho justas a partir da correta mensuração da contribuicão das atividades e das áreas para o resultado global da empresa;

- suportar e permitir simulaçōes e avaliação das decisões tomadas na empresa

- induzir comportamentos adequados dos gestores;

- não permitir o repasse de ineficiências entre as áreas

- promover a capacidade competitiva da empresa

A proposta de Pereira e Oliveira (1999) para alcançar esses objetivos é a utilização do conceito econômico de custo de oportunidade ${ }^{13}$, partindo da

premissa de que o valor dos produtose serviçostransacionados entre as unidades deveria refletir o valor do benefício possivel de ser auferido na melhor alternativa econômica de obtenção dos bens e serviços demandados (Pereira e Oliveira, 1999:421).

Esclarecem que a melhor alternativa econômica é a que

possibilite á organização o maior incremento de resultado econômico possivel, (...) a partir das opçōes de uso alternativo do produto de uma determinada área, [e que] o conceito é válido quando, além de existirem alternativas diferentes para a obtençāo de recursos, essas alternativas estejam ao alcance dos gestores, dentro de seus limites de autoridade e responsabilidade (Pereira e Oliveira, 1999:423)

\footnotetext{
13. Definido como "o custo da escolha de uma alternativa em detrimento de outra capaz de proporcionar um maio
} beneficio" (Pereira e Oliveira, 1999:415) 
O conceito econômico de custo de oportunidade, portanto, é tratado pòr Pereira e Oliveira como o custo de oportunidade para a área "receptora" do produto serviço (melhor alternativa de obtenção). O custo de oportunidade para a área "fornecedora" do produto/serviço (melhor alternativa de venda) não é considerado Entretanto, no caso do café da manhã, poder-se-ia perguntar se o custo de oportunidade para A\&B também não seria relevante, em alguns casos, para fins de análise $\mathrm{d} \in$ desempenho.

Se a área "fornecedora" - A\&B, neste caso - tiver a alternativa de vender o produto no mercado, e a área "receptora" - Hospedagem - tiver a alternativa de adquirir o produto no mercado, o modelo de valorização das transações internas baseado no custo de oportunidade poderia implicar estabelecimento de um duplo preço de transferência, sempre e quando existir limitação de capacidade de produção da área "fornecedora" e o produto/serviço transferido puder ser vendido como produto final:

- custo de oportunidade para a área receptora: o menor preço de mercado do produto/serviço transferido;

- custo de oportunidade para a área fornecedora: o melhor preço pelo qual o produto poderia ser vendido no mercado.

Algumas desvantagens são apontadas por Horngren, Fostere Datar(1997:644) quando são utilizados dois métodos separados de determinação do preço de transferência, gerando valores de transferência distintos para cada uma das duas áreas envolvidas na transação:

- o lucro operacional da organização como um todo é menor do que a soma dos lucros operacionais de cada subunidade;

- a subunidade fornecedora não tem motivação para controlar os custos;

- os gerentes podem ficar confusos em relação ao grau de descentralização procurado pela empresa.

Para Horngren, Foster e Datar (1997:639),

em termos ideais, o método de preço de transferência escolhido deve levar o gerente de cada subunidade a tomar as melhores decisões para a organização como um todo, [ajudando a] cumprir as estratégias e metas da organização e ajustar a sua estrutura.

Ainda segundo os mesmos autores, isso se traduz em:

- promover a congruência dos objetivos;

- promover um alto nível sustentado de empenho administrativo;

- estimular um alto nível de autonomia de decisão da subunidade.
Para que isso ocorra, não há uma regra universal. As possibilidades metodológicas de estabelecimento do preço de transferência e seus resultados devem ser avaliados para cada caso específico, e neste estudo serão analisadas em função do caso do café da manhã hoteleiro.

\section{Repasse de Café da Manhā}

Para que se possa analisar metodologias de determinação de preços de transferência para o café da manhã, é necessário, em primeiro lugar, entender algumas particularidades da prestação desse serviço.

\section{Gastos Variáveis e Semivariáveis do Serviço de Café da Manhã}

Gastos variáveis são os "custos e despesas cujos valores variam em proporção direta ao volume de vendas (ou receitas)". Gastos semivariáveis são "custos ou despesas que tem uma parte do seu valor fixo mas, em geral, variam com o volume de vendas" ('Tuch, 2001:1115-6).

No caso do café da manhã, e à primeira vista, o gasto variável mais óbvio é o custo da mercadoria vendida (CMV).

No entanto, aproximação às peculiaridades do serviço de alimentação mostrará que o CMV do café da manhã não é tão-somente resultado direto da quantidade vendida e custo da matéria-prima, ainda que se desconsiderem variações no preparo dos alimentos. Quando o serviçoé do tipo bufê, ou quando servido à mesa com opções de pedidos (sucos, cereais, iogurtes etc.), a quantidade consumida de matéria-prima no café da manhã pode variar em função do tipo de público. Hotéis que utilizam exatamente a mesma composição de café da manhã, ao mesmo custo, podem sofrer variações em função da quantidade consumida por pessoa: o CMV do café da manhã unitário não será apenas função do número de cafés vendidos, mas da qu

prima utilizada é função do volume de vendas de cafés e da quantidade consumida em cada café

em geral, CMV mais alto que hotéis de negócios, especialmente quando o horário do serviço nos hotéis de lazer prolonga-se até mais tarde. Ou ainda, um mesmo hotel distintos CMV

O CMV realizado do café da manhã hoteleiro é mensurado em termos médios, resultado do inventário do período dividido pelo número de pessoas atendidas. A variação de desempenho de custo realizado em relação ao custo padrão deriva de volume de venda, custo da matéria-prima e volume de matéria-prima, mas 
o volume de matéria-prima. em serviços de alimentação, é resultante não só da variação de eficiência, mas também resultante do padrão do consumidor ${ }^{14}$. Ainda assim, o CMV é o exemplo mais claro de gasto variável

Outros gastos variáveis são a despesa de lavagem de enxoval, ou de utilização de utensílios descartáveis. Material de consumo, como de escritório ou de limpeza são semivariáveis. Sob determinadas condições, é possível considerar também como variável ou semivariável a reposição do material de rodízio - cristais e vidros, louças e porcelanas, talheres, baixelas e prataria -, o gás de cozinha, a energia elétrica e a depreciação econômica de móveis e equipamentos.

Uma dificuldade agravante para análise dos gastos variáveis e semivariáveis ocorre quando o departamento de A\&B serve outras refeições e serviços, além do café da manhã Nesses casos, que são o da maioria de hotéis de grande porte, há a produção conjunta: os esforços de compras e de recebimento da mercadoria, a estocagem, o fluxo de informações, a mão-de-obra e os ativos para o processamento do alimento, a mão-de-obra do serviço de sala, as atividades de gestão e controle e, muitas vezes, a própria mercadoria utilizada ${ }^{15}$ são $\operatorname{conjuntas}^{16}:$ a análise de gastos com o café da manhã em particular não pode ser feita de forma objetiva. É por esse motivo que o SUCH propõe a discriminação das receitas de vendas, mas considera as despesas de alimentos e bebidas de forma conjunta.

\section{Gastos Fixos e Semifixos do Serviço de Café da Manhã}

Gastos fixos são custos ou despesas que não variam a curto prazo em função da variação do volume de vendas, enquanto gastos semifixos são custos ou despesas que não se alteram com pequenas variações do volume de vendas, mas variam com grandes variações de vendas (Tuch, 2001:III8).

São poucos os gastos de café da manhã que se enquadrariam como fixos, ao menos considerando que a maioria dos hotéis utiliza o SUCH, que orienta a não ratear gastos (custos e despesas de departamentos não operacionais). O aluguel, quando se aplica, é um exemplo de gasto fixo incorrido.

A mão-de-obra para o serviço de café da manhã (de cozinha e de sala) é em geral semifixa, bem como as despesas de manutenção e administração.

14. $\Lambda$ respeito de avaliação de desempenho, ver Guerreiro (1996)

5. Por exemplo, quando as frutas do bufê de sobremesa do jantar do dia anterior são reprocessadas para serem servidas como salada de frutas no café da manhă

6. Entende-se por produçao conjunta "o aparecimento de diversos produtos a partir, normalmente, da mesma matériaprima" (Martins, 1996:177)
Café da Manhã como Produto complementar à Hospedagem

Não se pode esquecer que o café da manhã é um produto complementar em relação ao serviço de acomodação proporcionado por um hotel. A opção por um hotel não se faz somente pelo café oferecido, mas também em função dele. Se a qualidade do café da manhã está aquém das necessidades e expectativas da demanda, o hotel pode perder volume de vendas de diárias. Por outro lado, A\&B também depende da boa qualidade dos serviços de hospedagem para vender o seu produto.

Pesquisas na área da indústria da hospitalidade, e até do turismo como um todo, praticamente inexistem no Brasil. No entanto, pode-se imaginar que as pesquisas a respeito das necessidades e expectativas da demanda teriam resultados próximos aos obtidos nos Estados Unidos. Hall (1990:87-136) desenvolveu, em conjunto com a American Hotel and Motel Association (AH\&MA) e o Citicorp/ Diners Club, uma pesquisa para averiguar os dezpequenos problemas mais freqüentes encontrados por hóspedes em suas estadas em hotéis. Dentre eles, encontra-se o problema do serviço de alimentação insatisfatório.

\section{Alternativas ao Serviço de Café da Manhã: custo de oportunidade}

O conceito de custo de oportunidade pressupõe a existência de alternativas. No caso do café, há alternativas tanto para o departamento fornecedor, de A\&B, quanto para o de Hospedagem. No entanto, talvez as alternativas não sejam as melhores opções para o empreendimento como um todo, exatamente em função da relação complementar existente entre o serviço de acomodação e o de alimentação. E, diferentemente da condição observada por Pereira (1999) para que o conceito de custo de oportunidade aplicado ao preço de transferência seja válido, nem sempre as alternativas estão dentro da alçada de autoridade e responsabilidade dos gestores dos departamentos.

As alternativas de Alimentos e Bebidas são basicamente duas: não fornecer o café da manhã a um "intermediário" (Hospedagem), ou não oferecer o serviço de café da manhã. De fato, muitas vezes o serviço de café da manhã, se analisado isoladamente, é deficitário, ainda que considerados apenas os gastos diretos, e dependendo do preço de transferência praticado. Ou, algumas vezes, pode ser deficitário ainda que pratique preços de mercado. Do ponto de vista departamental, nessas situações seria melhor simplesmente deixar de oferecer o serviço. Entretanto, o complexo hoteleiro, dependendo de sua localização, de seu conceito, de seu público e de sua categoria, jamais poderá dizer ao senhor hóspede: "queira, por gentileza, fazer o favor de ir tomar o café da manhã no boteco da esquina". A alternativa pode existir apenas para alguns hotéis de negócios econômicos, em raras 
situações - sob o risco de perder a clientela para seu produto principal, a hospedagem.

O problema de não fornecer o café da manhã a um "intermediário", vendendo-o somente diretamente aos hóspedes ou passantes, pode ser o mesmo. Se o grupo concorrencial pratica diárias com café da manhã incluso, e essa é uma das demanda do público-alvo, a organização como um todo pode perder clientes. Por outro lado, ainda que a taxa de ocupação hoteleira se mantenha constante após a decisão de não incluir o café da manhã na diária, nada garante que os hóspedes tomariam o café no hotel: dependendo da elasticidade da demanda, a receita de A\&B poderia sofrer uma queda resultante de um preço maior e de um volume de vendas menor, especialmente quando há opções de estabelecimentos de alimentação nas cercanias ${ }^{17}$. Assim sendo ainda que o departamento de A\&B possua autonomia suficiente para optar por quaisquer das alternativas e não oferecer o serviço de café incluso da diária, a avaliação do custo de oportunidade pode ser muito complexa.

A limitação da capacidade de produção, que implicaria a existência de uma alternativa simples - servir o café aos hóspedes, como café incluso ou como café extra, e aos passantes -, praticamente inexiste. Sempre haverá uma opção, mesmo em caso de limitação de espaço físico no restaurante e/ou de assentos e mesas: serviço de quarto, ou à americana etc. Então, as variáveis a serem consideradas seriam outras, como qualidade, possibilidades da operação de serviço alternativo, remodelação ou novos investimentos em equipamentos ou instalações, e assim por diante.

Em relação au departamento de Hospedagem, a alternativa é terceirizar o serviço. De fato, é a decisão que grande parte dos flats vem tomando. A decisão pela terceirização passa pela consideração de três questões principais, em termos de vantagens e desvantagens: a da qualidade do serviço prestado, a da rentabilidade do serviço (ou a ausência de) e a da complexidade operacional da prestação própria ${ }^{18}$ Sem querer entrar nessa discussão com profundidade, o que fugiria do escopo deste trabalho, pode-se afirmar que a terceirização do serviço dentro do próprio hotel privilegia a dedicação dos gestores ao principal produto hoteleiro - a unidade habitacional -, em detrimento da atenção a outras necessidades do hóspede: na maioria das vezes a terceirização traduz-se na queda da qualidade do serviço prestado, exatamente pelo fato do arrendatário privilegiar a rentabilidade.

Em suma, tanto o departamento de A\&B como o de Hospedagem obtêm ganhos da venda "casada" de diárias com café, desde que haja mercado para realizála. Alimentos e Bebidas tem a venda garantida sem necessitar do esforço de venda Hospedagem tem seu próprio produto valorizado pelo produto complementar. Resta verificar qual tem sido o tratamento contábil do repasse do café da manhã pelo mercado.

17. Esse é um problema que ocorre em grandes complexos de serviços, que possuem, além do hotel e de seus pontos de venda de alimentação, torres de escritórios, de eventos e shoppings, dotados de praças de alimentação comcasas de chà e coffece shops que podem oferecer o serviço.

18. A questâo do investimento não é mencionada jả que, na maioria das vezes, é efetuado pelo empreendimento hoteleiro. mesmo que para ser operado por terceiros.
Tratamento sugerido pela Literatura de Contabilidade Hoteleira

O Sistema Uniforme de Contabilidade para Hotéis (1996) não avalia os critérios que devem ser observados para determinar preços de transferência entre as áreas de produção de meios de hospedagem.

Cote (1997) trata de preços de transferência em hotelaria apenas brevemente, e referindo-se à lavanderia e à refeição de funcionários, não mencionando o repasse de café da manhã. Isso é compreensível, pois, como já foi mencionado, os meios de hospedagem norte-americanos em geral não incluem o café na diária. Em relação à transferência de lavanderia, Cote (1997:52) recomenda alocar "todos os custos" aos departamentos usuários do serviço interno, sem no entanto entrar em detalhes sobre o assunto.Tratando de refeições, Cote chega a sugerir a utilização de custo padrão:

As refeições de funcionários devem ser cobradas de cada departamento. Alguns hotéis utilizam o custo real da refeição, mas pequenas propriedades podem não ter a informações ou funcionários disponiveis imediatamente para manter tais registros detalhados. Nesses casos, a média típica de custo de uma refeição de funcionário deve ser tirada para chegar a um custo padrão para cada tipo de refeição: café da manhã, almoço ou jantar (Cote, 1997:59)

No índice remissivo de Moncarz e Portocarrero (1986:377-91) não se encontra a expressão transfer price, e nenhuma palavra sobre repasses ou transferências no capítulo dedicado à responsibility accounting, apesar de ser um livro sério e abrangente. Tampouco Schmidgall (1990) dá atenção ao assunto; o mesmo ocorre com Gray (1996).

A bibliografia nacional sobre questões contábeis hoteleiras praticamente inexiste. Zanella (s/d:80) menciona simplesmente que

quando a tarifa estabelecida para o hóspede inclui refeições, para efeito de apropriação correta das receitas de cada setor ou centro de custos, deve ser feito o respectivo desdobramento em receitas de serviços e receitas de produtos vendidos.

Não foram encontradas outras referências ao assunto, o que leva a crer que 0 assunto careça de estudos e reflexão. 


\section{Tratamento Contábil pela Hotelaria Paulistana: estudo exploratório}

O software especifico para hotelaria líder internacional, o Fidelio, prevê o repasse automático diário do preço de transferência de café da manhã, da receita de Hospedagem para a receita de A\&B. O software líder nacional, da CM Soluções do Rio de Janeiro, faz o mesmo. Seguem essa trilha muitos softwares semicaseiros desenvolvidos por programadores independentes que tenham se preocupado minimamente com as peculiaridades da hotelaria. Assim, o valor de repasse pode ser conhecido por qualquer recepcionista do hotel com senha de acesso, uma vez que se encontra cadastrado no front office.

Nesta pesquisa de campo com hotéis da cidade de São Paulo, no entanto, procurou-se conhecer não apenas o valor de repasse praticado, para compará-lo com custos e com o preço de venda, mas também os critérios que levaram o hotel a adotar um ou outro valor. A informação não foi fácil de ser obtida, menos por sigilo das empresas que por absoluta falta de critério. As entrevistas realizadas com os controllers ou gerentes administrativos dos hotéis foram muitas vezes improdutivas, nesse sentido. O que se pode generalizar são os preços de transferência praticados que se situam sempre entre o CMV e o preço de venda, como pode ser observado na tabela 7 .

De acordo com os critérios estabelecidos para essa pesquisa, os trinta primeiros hotéis classificados encontram-se listados. Depois deles, encontram-se os hotéis da cidade de São Paulo que possuem mais de 100 UH, de médio e grande porte, em ordem decrescente. A exceção é o hotel Deville, de Guarulhos, incluído por sua importância junto ao Aeroporto Internacional de Cumbica

Os hotéis que não possuem café da manhã incluído, ou que o fazem apenas raramente, não possuem valor de repasse estabelecido. Alguns hotéis possuem preço diferenciado no caso de passantes ou café extra de hóspedes, e no caso o valor que está relacionado é o preço de venda para hóspedes, já que é esse o parâmetro de preço praticado que interessa comparar com o preço de transferência.

O custo da mercadoria vendida para o café é o único dado de custo variável tomado por referência, já que os estabelecimentos hoteleiros pesquisados não utilizam nenhum outro para o estabelecimento do valor de repasse. O porcentual indicado é em relação ao preço de venda.
TABELA 7 - HOTÉIS E PREÇOS DE TRANSFERÉNCIA PRATICADOS

\begin{tabular}{|c|c|c|c|c|c|c|c|}
\hline \multirow{2}{*}{ Chssiticaçäo (") } & \multirow{2}{*}{ Hotel } & \multirow{2}{*}{ Całé lncuso } & \multirow{2}{*}{$\frac{\text { Preço }}{\text { PS }}$} & \multicolumn{2}{|c|}{ CMN } & \multicolumn{2}{|c|}{ Preço transferência } \\
\hline & & & & PS & $\%$ & $\mathrm{BS}$ & $\%$ \\
\hline 1 & Renaissance & só UH Club & & $n / i$ & - & - & - \\
\hline 2 & Melá & nāo & 30,00 & $n i$ & - & - & . \\
\hline 3 & Maksoud Plaza & nāo & 28,00 & ni & - & - & - \\
\hline 4 & Sofitel & nāo & 27,00 & $\mathrm{n} / \mathrm{i}$ & . & & \\
\hline 5 & L'Hotel & nāo & 22,00 & 8.50 & $38 \%$ & . & - \\
\hline 6 & Intercontinental & negociável & 22,00 & 5,50 & $25 \%$ & $22, \infty$ & $100 \%$ \\
\hline 7 & Caesar Park & sim & 29,00 & 9,27 & $32 \%$ & 17,40 & $60 \%$ \\
\hline 8 & Sheraton & nāo & 31,00 & ni & - & - & - \\
\hline 9 & Transamérica & $\operatorname{sim}$ & 22,00 & $\mathrm{n} / \mathrm{i}$ & - & ni & - \\
\hline 10 & Grand Hotel Mercure & fim semana & 17,00 & 3,45 & $20 \%$ & $17, \infty$ & $100 \%$ \\
\hline 11 & Golden Tuip Paulista PI. & $\operatorname{sim}$ & 18,00 & $\mathrm{n} / \mathrm{i}$ & . & 13,00 & $72 \%$ \\
\hline 12 & Blue Tree Berrini & $\operatorname{sim}$ & 19,00 & 9.90 & $52 \%$ & 19,00 & $100 \%$ \\
\hline 13 & Hillon & só pacotes & 16,00 & 7.00 & $44 \%$ & 7,00 & média \\
\hline 14 & Crowne Plaza & só pacotes & 23,50 & 6,00 & $26 \%$ & 10,50 & $45 \%$ \\
\hline 15 & Ca'd'Oro & $\operatorname{sim}$ & 18,00 & 3,00 & $17 \%$ & 9,00 & $50 \%$ \\
\hline 16 & Novotel Center Norte & só pacotes & 12,00 & $\mathrm{n} / \mathrm{i}$ & - & - & - \\
\hline 17 & Golden Tuip Park Paza & $\operatorname{sim}$ & 19,00 & $\mathrm{ni}$ & - & 10,00 & $53 \%$ \\
\hline 18 & Blue Tree Naçōes & $\operatorname{sim}$ & 15,00 & \multicolumn{2}{|c|}{ terceirizado } & 7,00 & $47 \%$ \\
\hline 19 & Pérganion & $\operatorname{sim}$ & 14,00 & 3,50 & $25 \%$ & 3,50 & $25 \%$ \\
\hline 20 & Meliá Confort Brooklin & $\operatorname{sim}$ & 12,00 & \multicolumn{2}{|c|}{ terceirizado } & 8.00 & $67 \%$ \\
\hline 21 & Best Western Porto do Sol & sim & 18,00 & 4.80 & $27 \%$ & $n i$ & . \\
\hline 22 & Novotel Morumbi & $\operatorname{sim}$ & 14,00 & ni & - & $n_{i}$ & . \\
\hline 23 & EZ Paza Jardins & $\operatorname{sim}$ & 14,00 & 5,20 & $37 \%$ & 8,50 & $61 \%$ \\
\hline 24 & Melá Confort ttaim & $\operatorname{sim}$ & 15,00 & $\mathrm{n} / \mathrm{i}$ & - & $n / 1$ & - \\
\hline 25 & Estanplaza Naçōes Unidas & $\operatorname{sim}$ & 16,00 & 2,90 & $18 \%$ & 10,00 & $63 \%$ \\
\hline 26 & Bourbon & sim & 16,00 & 6,50 & $41 \%$ & 16,00 & $100 \%$ \\
\hline 27 & Estanplaza Berrini & $\operatorname{sim}$ & 16,00 & $\mathrm{nii}$ & - & 9,80 & $61 \%$ \\
\hline 28 & Della Vobe Garden & $\operatorname{sim}$ & 20,00 & ni & - & $n / i$ & - \\
\hline 29 & Sol Pamplona & $\operatorname{sim}$ & 15,00 & 3.80 & $25 \%$ & 8,00 & $53 \%$ \\
\hline 30 & Nikkey Palace & $\operatorname{sim}$ & 16,00 & ni & - & 15,40 & $96 \%$ \\
\hline 40 & tbis Expo & nāo & 7,00 & \multicolumn{2}{|c|}{ não apura } & - & - \\
\hline 50 & Tropical & $\operatorname{sim}$ & 18,00 & 2,10 & $12 \%$ & 7.40 & $41 \%$ \\
\hline 31 & Braston & $\operatorname{sim}$ & 12,00 & 5,00 & $42 \%$ & 10,00 & $83 \%$ \\
\hline 46 & São Paulo Othon Cla ssic & $\operatorname{sim}$ & $11, \infty$ & 4.07 & $37 \%$ & 4.00 & $36 \%$ \\
\hline 52 & San Raphael & sim & 13,00 & 2,75 & $21 \%$ & 2,75 & $21 \%$ \\
\hline 53 & Century Paulista & $\operatorname{sim}$ & 10,00 & 2,90 & $29 \%$ & $10, \infty$ & $100 \%$ \\
\hline 56 & Exceisior & $\operatorname{sim}$ & 12,00 & 5,00 & $42 \%$ & 5,00 & $42 \%$ \\
\hline 59 & Normandie Design & $\operatorname{sim}$ & 12,00 & ni & - & $\mathrm{Ni}$ & - \\
\hline 57 & Best We stern Augusta & $\operatorname{sim}$ & 18,00 & ni & . & $N i$ & . \\
\hline
\end{tabular}




\begin{tabular}{|c|c|c|c|c|c|c|c|}
\hline \multirow{2}{*}{ Classiticạ̧ão (") } & \multirow{2}{*}{ Hotel } & \multirow{2}{*}{ Caté Incuso } & \multirow{2}{*}{$\frac{\text { Preso }}{\text { PS }}$} & \multicolumn{2}{|c|}{ CMN } & \multicolumn{2}{|c|}{ Proço transferéncia } \\
\hline & & & & Ps & $\%$ & $\mathrm{RS}$ & $\%$ \\
\hline 41 & Eldorado Boulevaid & $\operatorname{sim}$ & 10,00 & $n_{i}$ & - & $n_{i}$ & - \\
\hline 43 & Pan Americano & sim & 13,50 & $n_{i}$ & - & $n_{i}$ & \\
\hline 35 & Eldorado Higienópolis & $\operatorname{sim}$ & 15,00 & 3,00 & $20 \%$ & 8,50 & $57 \%$ \\
\hline 34 & The Park Lane & sim & 15,00 & 4,30 & $29 \%$ & 4,30 & $29 \%$ \\
\hline 39 & Sol Bienal & $\sin$ & 12,00 & ni & - & $n_{i}$ & $\cdot$ \\
\hline 65 & Be st Western SP Inn & sim & 9,00 & ni & - & não & - \\
\hline GRU & Devile & sim & 15,00 & 4.50 & $30 \%$ & 6,70 & $45 \%$ \\
\hline 38 & Blue Tree Vila Olmpia & $\operatorname{sim}$ & 12,00 & & ado & 7,50 & $63 \%$ \\
\hline 44 & Pegent Park & $\operatorname{sim}$ & 11,00 & 2,00 & $18 \%$ & 2,00 & $18 \%$ \\
\hline
\end{tabular}

$\left({ }^{*}\right)$ conforme o Guia Quatro Rodas Brasil (2001).

- = o dado não se aplica

$\mathrm{n} / \mathrm{i}=$ hotel recusa-se $\mathrm{a}$ informar

A coluna de preço de transferência é o valor de repasse de receita praticado. Invariavelmente, é o valor cadastrado no software hoteleiro, que faz o repasse diário automaticamente. Exceções são:

- os hotéis Della Volpe Garden e Best Western Augusta que, difícil de acreditar, ainda trabalham com o sistema mecânico de máquinas Dismac, e portanto o repasse só pode ser realizado manualmente;

- o hotel Transamérica, que possui um software próprio

- os hotéis Normandie Design e Best Western São Paulo Inn, que utilizamo software APP, de São José do Rio Preto, que não prevê o repasse de café da manhã;

- o Eldorado Boulevard, que utiliza o JCombetto, que também não prevê a transferência. O porcentual indicado também foi calculado em relação ao preço de venda.

Os 48 estabelecimentos pesquisados possuem um preço de venda estabelecido para o café da manhã. Oito hotéis $(16,7 \%)$ não incluem o café da manhã na diária ou, nas poucas vezes quando o fazem, o tratam da mesma forma que se estivesse sendo vendido separadamente: Renaissance, Gran Meliá São Paulo, Maksoud Plaza, Sofitel São Paulo, L'Hotel, Sheraton, Novotel Center Norte e Ibis Expo. Sete hotéis $(14,6 \%)$ praticam um preço de transferência de igual valor ao preço praticado Intercontinental, Mercure, Blue Tree Caesar Towers Berrini, Bourbon, Century, Nikkey Palace e Braston. Os dois últimos estão incluídos nesse grupo, apesar de transferirem uma receita ligeiramente menor que o preço praticado, uma vez que, conforme informações obtidas, o critério é o preço de venda, apesar de terem "esquecido" de modificar o valor no software quando houve majoração do preço do café da manhã. Nove hotéis (18,7\%) utilizam-se do conceito conhecido por prime cost , "denominação eminglês para custos primários deprodução, que compreendem matéria-prima e mão-de-obra" (Fonseca, 2000:97). Desses nove, quatro hotéis (Caesar Park, EZ Plaza Jardins, Estanplaza Nações Unidas e Estanplaza Berrini) trabalham com o prime cost padrão da indústria, de $2 / 3$ ou $60 \%$, e cinco (Golden
Tulip Paulista Plaza, Ca'd'Oro, Golden Tulip Park Plaza, Eldorado Higienópolis e Deville) trabalham com critérios para determinação de seu próprio prime cost padrão.

Seis hotéis $(12,5 \%)$ definem o valor de repasse conforme o CMV. Um deles, o São Paulo Othon Classic Hotel, utiliza o CMV padrão para a indústria (1/3 ou $30 \%$ ), enquanto os demais (Pérgamon, San Raphael, Excelsior, The Park Lane e Regent Park) utilizam seu próprio CMV padrão, baseado no CMV histórico.

Quatro hotéis possuem o restaurante terceirizado e, portanto, não cabe o conceito de preço de transferência: Blue Tree Caesar Towers Nações, Meliá Confort Brooklin, Sol Pamplona e Blue Tree Caesar Towers Vila Olímpia.

O Hilton define o valor de repasse caso a caso, quando há a necessidade de incluir o café da manhã nas diárias de grupos. O Crowne Plaza declarou utilizar-se do CMV padrão mais uma margem, apesar de a margem não estar claramente definida. O Tropical Planalto, curiosamente, estabelece o preço de transferência "checando o porcentual da receita de A\&B em relação à receita total e procurando com isso, um valor razoável de repasse". Parece que o critério é político, e o valor transferido maior ou menor em função da necessidade de atingir o orçamento.

Onze hotéis $(22,9 \%)$ não souberam ou quiseram informar (Transamérica, Best Western Porto do Sol, Novotel Morumbi, Meliá Confort Itaim, Della Volpe Garden, Normandie Design, Best Western Augusta, Eldorado Boulevard, Panamericano, Sol Bienal e Best Western São Paulo Inn). Os resultados obtidos estão representados na tabela 8 e figura 1 .

TABELA 8 - CRITÉRIOS UTILIZADOS PARA PRECO DE TRANSFERÉNCIA DO CAFÉ DA MANHÄ NOS HOTÉIS DE ALTA CATEGORIA E GRANDE PORTE DE SÃO PAULO

\begin{tabular}{ll|c|c}
\hline $\begin{array}{c}\text { Modelo de Preço de } \\
\text { Transferéncia }\end{array}$ & $\begin{array}{c}\text { Número de } \\
\text { Hotéis }\end{array}$ & $\%$ \\
\hline Não incluem café & padrão & 8 & $16,7 \%$ \\
Preço de venda & 7 & $14,6 \%$ \\
Prime cost & indústria & $8,3 \%$ \\
padrão & 5 & $10,4 \%$ \\
CMV & padrão & 1 & $2,1 \%$ \\
Terceirizado & indústria & & $10,4 \%$ \\
Outros & padrão & 5 & $8,3 \%$ \\
Não informaram & & 4 & $6,3 \%$ \\
\hline TOTAL & & 3 & $22,9 \%$ \\
\hline
\end{tabular}




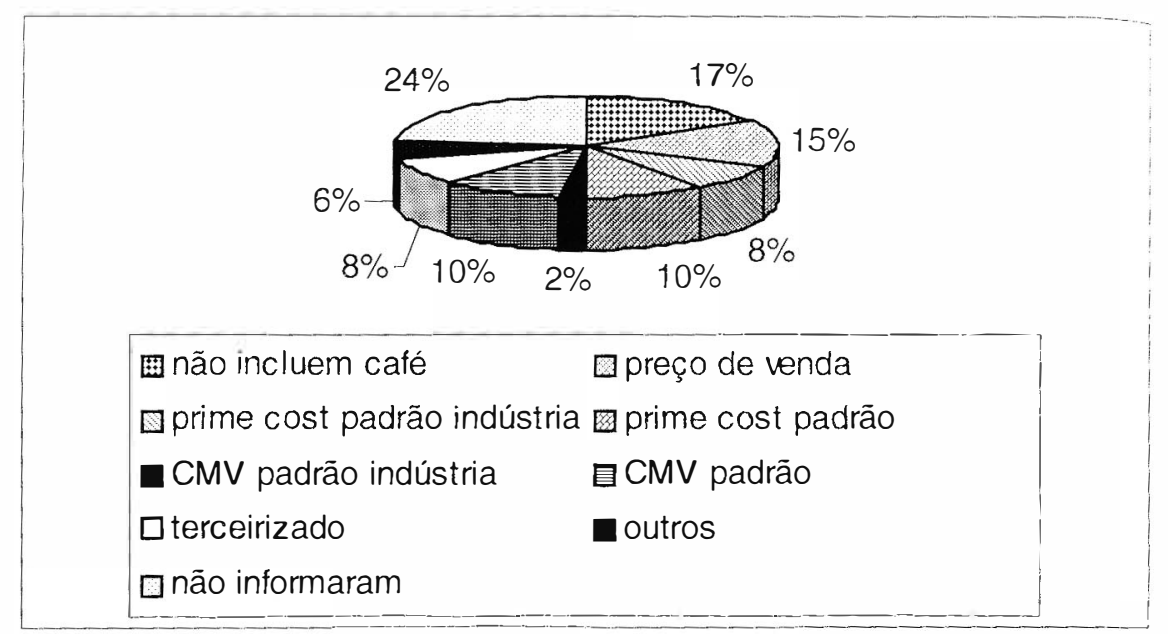

\section{FIGURA 1 - CRITÉRIOS UTILIZADOS PARA PREÇO DE TRANSFERÊNCIA DO} CAFÉ DA MANHÃ NOS HOTÉIS DE ALTA CATEGORIA E GRANDE PORTE DE SÃO PAULO

É curioso observar que não existe um critério único sendo utilizado dentro da mesma rede hoteleira. A percepção obtida com essa pesquisa, mais pelas entrevistas realizadas que pelos resultados em si, é que as controladorias hoteleiras dão pouca importância ao valor de transferência, ao mesmo tempo em que, paradoxalmente, preocupam-se com o resultado departamental de A\&B.

\section{Considerações Finais}

Este estudo procurou demonstrar a relevância que pode ter o preço de transferência do café da manhã para a análise de resultados departamentais das empresas hoteleiras. Buscou na literatura contábil e específica do segmento de hospitalidade subsídios teóricos que auxiliassem a esclarecer os critérios passíveis de consideração para a determinação de tal preço, ao mesmo tempo em que foi buscar, junto ao mercado hoteleiro da cidade de São Paulo, informações sobre como a transferência de receita vem sendo praticada.

Retomando as metodologias indicadas por Pereira e Oliveira (1999) foram feitas as seguintes observações em relação ao café da manhã (Tabela 9).

Para Horngren, Foster e Datar (1997:642) preços de transferência baseados no custo são úteis quando o produto é específico ou único. O CMV do café da manhã, tratado como o principal custo variável e uma aproximação ao custo marginal, deve ser o mín imo preço de transferência, para não penalizar os resultados do departamen- to de A\&B. Horngren, Foster e Datar (197:644) apresentam uma diretriz geral como "um primeiro passo muito útil para a determinação do preço mínimo de transferência em situações específicas":
Preço de trarsferência $=$ custo incremental ou desembolso + custo de oporturidade unitário da minimo incremertal adicionais por uridade. divisão fornecedora

O máximo, obviamente, é o preço de venda praticado - que coincide, neste caso, com o custo de oportunidade do departamento fornecedor -, sob pena de prejudicar os resultados do departamento de Hospedagem. A questão fundamental é o ponto, entre o CMV e o preço praticado, que o preço de transferência deve ficar.

Estabelecer o preço de transferência do café da manhã igual ao preço praticado pode dar margem de contribuição muito grande ao café da manhã, que não necessita de esforço de vendas do departamento de A\&B, e desestimular o gestor a promover a venda de outros produtos e serviços de alimentos e bebidas. Ou, ainda, estimular desperdícios.

TABELA 9 - TIPOS DE PREÇOS DE TRANSFERÊNCIA DE CAFÉ DA MANHÃ PRATICADOS

\begin{tabular}{|c|c|c|}
\hline Base & Tipo & $\begin{array}{l}\text { Café da manhã na hotelaria } \\
\text { paulistana }\end{array}$ \\
\hline \multirow[t]{5}{*}{ Custos } & full cost / prime cost & $\begin{array}{l}\text { O full cost não é utilizado. O prime cost, } \\
\text { padrão da indistria ou do } \\
\text { estabelecimento, é o que foi encontrado } \\
\text { na pesquisa. }\end{array}$ \\
\hline & Custo variável & Nāo ülizado. \\
\hline & Custo variável padrão & Não utilizado. \\
\hline & Custo margiral & $\begin{array}{l}\text { Utilizado CMV padrāo da indústria ou do } \\
\text { estabelecimento, que é uma } \\
\text { aproximação ao custo marginal. }\end{array}$ \\
\hline & Custo mais margem & Utilizado CMV mais margem. \\
\hline Negociação & Negociaçāo entre gestores & $\begin{array}{l}\text { Ocorre, em geral, tomando-se por base } \\
\text { o CMV padrão da indústria / do } \\
\text { estabelecimento e o preço praticado. } \\
\text { Aproxima-se, no caso do café da manhã, } \\
\text { ao método de CMV mais margem: a } \\
\text { margem pode ser negociada. }\end{array}$ \\
\hline $\begin{array}{l}\text { Preço de } \\
\text { mercado }\end{array}$ & Preço praticado & $\begin{array}{l}\text { Preço praticado é o único critério de } \\
\text { preço de mercado utilizado por um } \\
\text { seviço que não tem correspondente } \\
\text { idêntico no mercado. }\end{array}$ \\
\hline Ecorômica & Custo de oportunidade & $\begin{array}{l}\text { Não se aplica ao caso do café da } \\
\text { manhāa especialmente por razão da } \\
\text { inexistência de autonomia dos ges tores } \\
\text { departamentais para decidir comprar ou } \\
\text { fornecer o serviço externamente como } \\
\text { alternativa à transferência interna. }\end{array}$ \\
\hline
\end{tabular}


Por outro lado, o preço de transferência baseado no CMV pode causar o mesmo resultado, se o departamento se entende prejudicado e "desiste" de produzir um bom resultado. Conforme Mauro (1991:160), o preço de transferência fundamentado em qualquer noção de custo não motiva comportamentos adequados dos gestores, e não soluciona satisfatoriamente o problema de "intercâmbios de qualidade de gestão".

De qualquer forma, o critério "político" - de "ajuste" do preço de transferência para atendimento do orçamento - é o menos indicado para obter empenho dos gestores e congruência de objetivos: o preço de transferência deve ser estabelecido de tal forma que o orçamento seja um desafio e um estímulo, e não o contrário.

Fica aqui, como indicação para uma futura pesquisa, a consideração de quais podem ser as vantagens e desvantagens das práticas utilizadas pelos hotéis pesquisados dentro do contexto de cada organização, tentando estabelecer alguns parâmetros para a determinação do preço de transferência do café da manhã.

\section{Referências Bibliográficas}

COTE, Raymond. 1997. Understandinghospitality accounting /l. Michigan: Educational Instituteof the American Hotel \& Motel Association (EI-AH\&MA).

FONSECA, Marcelo Traldi. 2000. Tecnologias gerenciais de restaurantes. São Paulo: Senac

GUERREIRO, Reinaldo.1996. A meta. São Paulo: Atlas.

GUIA QUATRO RODAS BRASIL. 2001. São Paulo: Abril.

GRAY, William S. 1996. Hospitality accounting. New Jersey: Prentice Hall.

HALL, Stephen S. J. 1990. Quality assurance in the hospitality industry. Wisconsin: ASQC Quality Press.

HORNGREN, Charles T.; FOSTER, George; DATAR, Srikant M. 1997. Contabilidade de custos. Rio de Janeiro: LTC. HORWATH CONSULTING \& SOTECONTI AUDITORES INDEPENDENTES. 1999. A indi.stria hoteleira brasileira. São Paulo: Soteconti.

MARTINS, Eliseu. 1996. Contabilidade de Custos. São Paulo: Atlas.

Mauro, Carlos Alberto. 1991. Preço de transferência baseado no custo de oportunidade: un instrumento para a promoção da eficácia empresarial. Mestrado, Faculdade de Economia e Adninistração, Universidade de São Paulo.

MONCARZ, Elisa S. e PORTOCARRERO, Nestor de J. 1986. Financial accounting for hospitality management. Nova York: Van Nostrand Reinhold.

PEREIRA, Carlos Alberto. 1999. Avaliação de resultados e desempenhos. In: CATELLI,Amando(Org.). Controladoria: uma abordagem da gestão econômica GilCON. São Paulo: Atlas.

PEREIRA, Carlos Alberto e OLIVEIRA, Antonio Benedito Silva. 1999. Preço de transferência: una aplicação do conceito do custo de oportunidade. In: CATELLI, Amando (Org.). Controladoria: uma abordagem da gestão econômica GECON. São Paulo: Atlas

SCHMIDGALL, Raymond S. 1990. Hospitality industry managerial accounting. Michigan: Educational Institute of the American Hotel \& Motel Association (EI-AH\&MA).

TUCH, David Lord. 2001. Controles gerenciais hoteleiros. São Paulo: SENAC-CET.

UNIFORM SYSTEM OF ACCOUNTS FOR HOTELS. 1996. Michigan: Educational Institute of the American Hotel \& Motel Association (EI-AH\&MA).

ZANELLA, Luiz Carlos. s/d. Manual de contabilidade para hotéis e restaurantes. Porto Alegre: Pallotti

Recebido em 13/3/0I

Aprovado em 20/05/0I 